\title{
Rumination, realignment and reflection: Who is really teaching health education in secondary schools?
}

\section{Donna Barwood}

Edith Cowan University

donnabarwood@iinet.net.au

Keywords: health education, teacher education institutions. HPE, secondary education, pre-service teachers

\begin{abstract}
In Western Australia (WA), health education (HE) is timetabled as a separate, disciplinebased subject belonging to the health and physical education (HPE) learning area. Globally, this subject is identified as a key site to support and strengthen the health and wellbeing of children and young people. In WA, teachers from outside-of-the-field of HPE are commonly used to deliver HE. This situation is not exclusive to HE nor to WA, and in some circles is referred to as education's dirty little secret. This mixed-methods study critically examined the role of the teacher in the delivery of HE with the purpose of continuing previous WA-based research and responding to a gap in data with regard to the qualifications of the teachers. The study obtained questionnaire responses from 75 teachers delivering HE in 49 different lower secondary government schools across the state with nine teachers interviewed after the first round of quantitative data collection to provide contexualised information of the WA setting. The study found that half of the teachers delivering HE were unprepared to do so.
\end{abstract}

\section{Introduction}

Effective Health Education ( $\mathrm{HE}$ ) delivery in Australian schools is needed to contribute to the health and wellbeing of young Australians. Meanwhile, effective delivery in HE is characterised by quantity and quality, relying on a triangulated tension between policy, context and teacher preparedness to teach (Barwood, 2015a). Therefore, to survive and ultimately thrive amidst the dichotomy between theory and practice, $\mathrm{HE}$ in Australian schools must address challenges in teacher preparations and the particular ways in which it is defined by schools and teachers. Moreover, to make a meaningful difference in the lives of young Australians, HE must embrace the vertices of tension and develop ways to stimulate symbiosis.

This paper focuses on the preparation of a particular group of teachers who delivered HE in lower secondary government schools in WA in 2012. It stems from a mixed methods study (Barwood, 2015a) that sought to further previous but now dated WA research (Shilton, McBride, Cameron, \& Hall, 1995), which like other similar international studies investigated issues pertaining to teachers delivering $\mathrm{HE}$ without confirming the qualifications of these teachers through data (Barwood, 2015b; Barwood, Cunningham, \& Penney, 2017). In accepting the possibility of a gap in data, the study critically examined the qualifications and training of 75 teachers delivering HE with intent to develop more valuable spaces to support health learning in secondary schools. The study found that nearly half of the teachers delivering $\mathrm{HE}$ were categorised as unprepared to deliver the subject based on their undergraduate and 
graduate qualifications and training, whilst noting that teacher competence and confidence post qualification was somewhat dependent on attitude to teach the subject.

In light of data, this paper centres on developments, post-study, pertaining to the course structure of HPE pre-service teacher education at a particular WA-based university. It reports on progress to address and realign the university's perspective of pre-service teacher preparations in HPE. At the same time, this paper returns to data generated in the mixed method study to spotlight the incidence of 'out-of-field' teaching in the delivery of HE. In so doing, it aims to promote and renew open dialogue between schools, teacher education institutions and professional organisations such as the Australian Council for Health, Physical Education and Recreation as a means to support quality in HE delivery. This paper acknowledges that HE is variously delivered and offers suggestions for professional learning that could assist teachers to deliver effective HE in Australian schools.

\section{Background}

In Australia, schools as locators of formative dilemmas orchestrate the particular version of HE that is delivered, whilst teachers as enactors of State and Territorial curricula engender the meanings and ways in which children and young people are taught for and about health. Universities as mediators of curricula and practice, and in acknowledgment of educational settings prepare pre-service teachers with the knowledge, understandings and skills to effectively deliver HE in schools variously positioned. Simultaneously, universities recognise, acknowledge and ratify the Australian Professional Standards for Teachers through their course structures and learning opportunities (Australian Institute for Teaching and School Leadership, 2011a).

In 2012, most secondary schools in WA paired Physical Education (PE) with HE to present a holistic understanding of HPE, with Outdoor Education (OE) offered as an elective subject (Barwood, 2015a; Barwood, Cunningham, \& Penney, 2017). This representation is similar to other states and territories in Australia including: Australian Capital Territory, Northern Territory, Queensland, South Australia and Victoria, but differs slightly to the states of Tasmania and New South Wales (Barwood, 2015a; Leahy, Burrows, McCuaig, Wright, \& Penney, 2016). This combination of PE and $\mathrm{HE}$ has a somewhat longstanding tradition in WA with McBride, Midford and Cameron (1999) reporting that it was established with the introduction of the Curriculum Framework in 1998 (Western Australia Curriculum Council). In 2017, this combination will be continued via the formal implementation of the WA P-10 Syllabus for HPE (School Curriculum and Standards Authority, 2015), which legitimises the WA re-contextualisation of the endorsed Australian Curriculum for HPE (Australian Curriculum, 2015).

In 2012, four of the five teacher education institutions in WA effectively prepared pre-service teachers to deliver HPE in WA schools (Barwood, 2015a). The remaining university permitted enrolled students to graduate with a limited experience of HPE at variance to the preferred conceptualisation of HPE in WA and/or Australian schools. More particularly, through their unit selections, students in the course could preclude critical aspects of the HPE learning area resulting in an educational perspective that privileged $\mathrm{PE}$ and/or OE over $\mathrm{HE}$.

In 2016, the perspective remains incongruent with the holistic approach articulated in contemporary HPE (Australian Curriculum, 2015); pre-dating the earlier mentioned Curriculum Framework in WA (Education Department of Western Australia, 1986, 1987a, 1987b; Western Australia Curriculum Council, 1998). Some teachers refer to this perspective as a 'bug bear of the WA system' as the majority of pre-service HPE teachers in WA stemmed from this one university (Barwood, 2015a). 


\section{Teacher preparation}

Research suggests that teacher preparation is critical in supporting quality education (Australian Institute for Teaching and School Leadership, 2011b; Hattie, 2003, 2005, 2009) and from the perspective of HE rich international and national research agrees, citing issues with teacher comfort, confidence and competence as impacting what is and what is not taught in the name of HE (Begoray et al., 2009; Evans, Davies, \& Wright, 2004; Fetro, 2010; Kann et al., 2001; Paakkari, Tynjala, \& Kannas, 2010; Sinkinson, 2011; Smith \& Philpot, 2011; Tinning, $2000,2004)$. Equally, research concedes that teacher preparation has significant implications for the ways in which young people come to know health knowledge, primarily because HE is more vulnerable than other subjects to the diversity of personal perspectives. Burrows and Wright (2004) encouraged teachers, through their pedagogical choices, to "dissect, disrupt and perhaps transform student thinking about what constitutes and contributes to well-being and health" (p. 203) because as more recently explored by Leahy et al. (2016), teaching and learning that positions health within an individualistic perspective of personal responsibility is problematic.

With regard to teacher preparation for HE two groups of teachers are clearly identified, those who could be classified as inadequately prepared to teach the subject and those who could be classified as unprepared to teach. Harris and Leggett (2013) reported that teachers in England and Wales could be classified as inadequately prepared because HE was not included in their pre-service training. Paakkari et al. (2010) from the context of Finland, cited incidences of teachers of "home economics, biology, citizenship education and psychology delivering health education" (p. 917). They considered that it was difficult to know whether these teachers were delivering "all the critical aspects of teaching health education" (Paakkari et al., 2010, p. 917). McConney and Price (2009) in referring to unprepared teachers used the term 'out-of-field' to define them. They explain that 'out-of-field' teaching is a way for school administrators to "top-up" the timetable of a teacher (p. 89), and found that the incidence of this practise was much higher in the lower secondary years. Notably, McConney and Price reported that teachers timetabled to deliver Information Technology were the most significant group who lacked training at 46 per cent and more likely to be comprised from 'out-of-field' teachers.

From a more local perspective, WA researcher Daube (2011) criticised HE teacher preparations whilst another WA based research (Western Australia Education and Health Standing Committee, 2011) pointed more directly to the shortcomings in the course design for teacher preparations at WA universities (Barwood, Cunningham, \& Penney, 2017). Swabey, Castleton and Penney (2010) on researching the perceptions of beginning HPE teachers in Tasmania found that the key concern for these teachers was "practical pedagogical knowledge" (p. 34) and that is, knowing the content and how to teach it.

Irrefutably, teacher preparedness to deliver HE remains a global issue, with a raft of scholarship documenting how preparedness can impact student engagement with the broader meanings of health (Begoray et al., 2009; Burrows \& Wright, 2004; Fetro, 2010; Harris \& Leggett, 2013; Kann et al., 2001; Leahy et al., 2016; Lohrmann, 2011; Mayer, Smith, \& McDermott, 2011; Paakkari et al., 2010; Sinkinson, 2011; Smith \& Philpot, 2011). Drawing on the study's insights, this paper now details the methodology used for the study whilst exploring some challenges and opportunities to support teachers who deliver HE in secondary schools to develop meaningful and valuable spaces for health learning.

\section{Method}

Utilising mixed-methods methodology, the study collected quantitative data from 75 teachers in an online and paper survey and qualitative data from nine teachers who participated in 
semi-structured interviews. Analysis of the survey data was performed using SPSS (21) with descriptive statistics calculated. Analysis of qualitative data was performed using Artichoke computer software (Fetherston, 2011) as it was specifically designed for handling qualitative data in educational settings.

Analysis of the survey data determined the extent to which 49 lower secondary government schools in WA timetabled HPE teachers and 'out-of-field' teachers to deliver HE. Analysis of the interview data revealed the perspectives of a group of $\mathrm{HE}$ teachers and was combined with the quantitative data to produce contextual insight into the representation and delivery of $\mathrm{HE}$ in particular WA schools.

Ethical approval for the study was attained through Edith Cowan University and the Department of Education in WA. A review of historical and current developments in HPE curricula across Australia along with the course structures of WA universities that prepare HPE teachers for secondary schools, determined the extent to which HPE pre-service teachers in some WA secondary schools were prepared to deliver HE.

\section{Results and discussion}

\section{Age and gender}

Of the 75 participants, 37 were male, 36 were female and two participants identified with the 'other' category. The majority (33\%) of the participants were aged between 40 and 49 years, with the number of male participants declining thereafter according to age. Female participants did not show the same age distribution but declined between 30 and 39 years, and again after 50 years. The number of female participants aged between 20 and 29 years were comparable to that of female participants aged between 40 and 49 years.

\section{Participants' main learning area}

Sixty-five participants (86\%) identified the main learning area in which they taught as HPE, whilst 10 (14\%) participants identified learning areas other than HPE (Figure1). The literature (McConney \& Price, 2009), referred to this group of teachers as 'out-of-field' teachers, whilst the participants in the study referred to them as 'filler teachers'.

Figure1. Participants whose main learning area is other than HPE.

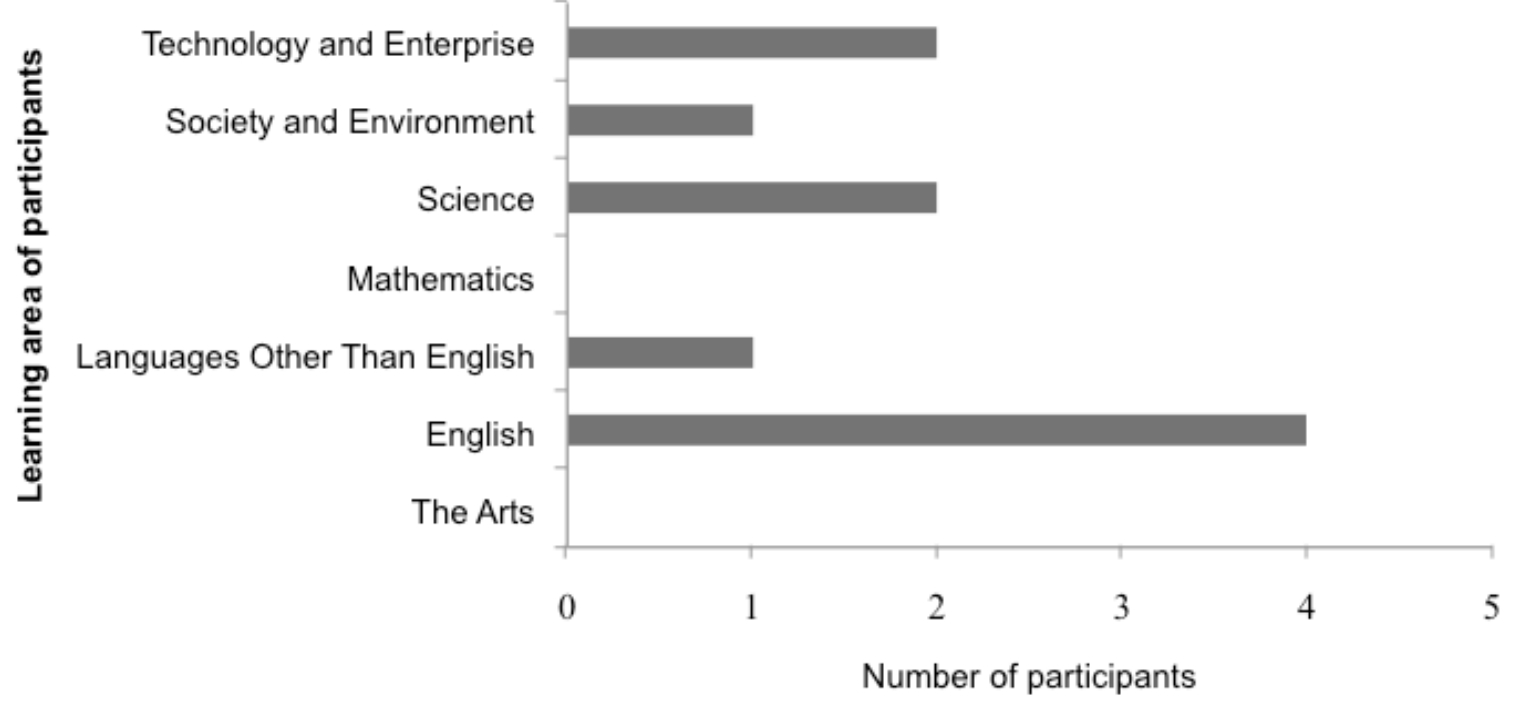


The largest grouping of the participants who were 'out-of-field' HE teachers (four) stated English as the main learning area, with the Mathematics and the Arts having no participants. As evidenced by the interview participants' statements, it is possible that teachers of Mathematics and the Arts at that time were in short supply in WA government schools, with those who taught these subjects having no extra time to deliver HE. Further, the participants reported that HPE teachers with a teaching minor such as Mathematics or the Arts were often used to fill perceived teacher shortages, which in turn impacted their availability to deliver HE.

When interviewed, the nine participants consistently complained about the use of 'out-of-field' teachers delivering HE in their schools and reported teachers such as French, Science, Society and Environment and the school librarian as timetabled to deliver the subject. They cited these teachers feeling uncomfortable and lacking confidence, ignoring and/or refusing to deliver the subject's essential content, using a didactic mode of delivery, disregarding the subject's skillbased approach, and losing valuable resources. One participant was infuriated by an 'out-offield' teacher, claiming that he refused to teach the subject even though she had written out every lesson plan for him. Another participant felt that 'out-of-field' teachers struggled with the way in which contemporary HE was taught and referred to learning experiences that explored, "self management skills and interpersonal skills" as problematic for these teachers. Another believed that 'out-of-field' teachers had a very "different framework in mind of how to teach" and that this framework did not include participatory activities.

The survey participants when given the opportunity for extended comment also complained about issues pertaining to timetabling and staffing that impacted the delivery of HE. Of the 36 written responses, the most frequent response $(50 \%)$ related to the use of teachers outside of HPE delivering HE. One teacher exemplified the participant responses by commenting that "health education has been often 'farmed out' to whoever is under loaded outside the PE faculty [HPE], which at times, has not been in the best interests of the students."

Although 'out-of-field' teaching is not an uncommon practice in schools across Australia, the 46.7 per cent of teachers in the study who were deemed to be either unqualified or without training in $\mathrm{HE}$ is high in comparison to incidences reported in other subjects (du Plessis, Gillies, \& Carroll, 2014; Goos, 2013; McConney \& Price, 2009).

\section{Participants' formal teaching qualification}

Following the questions pertaining to age, gender and main learning area taught, the participants were asked to identify with a category of teaching qualification. Of the 65 participants who stated HPE as their main learning area, Table 1 shows that 58 of the 65 teachers (89\%) have formal teaching qualifications in HPE, and seven (11\%) have no formal teaching qualification in HPE. At the same time, Table 1 shows that $18(28 \%)$ of the 65 participants, despite having a formal qualification in HPE, stated that the qualification was without HE training. 
Table 1. Participants' learning area and formal teaching qualification

\begin{tabular}{l|c|c}
\cline { 2 - 3 } \multicolumn{1}{c}{} & \multicolumn{2}{c}{ Learning Area } \\
\hline Formal teaching qualification & HPE & Other than HPE \\
\hline HPE qualification with HE & 40 & 0 \\
\hline HPE qualification without HE & 18 & 1 \\
\hline Non-HPE qualification with HE minor & 0 & 1 \\
\hline Non-HPE qualification without HE minor & 1 & 1 \\
\hline Post-graduate degree in health-related studies & 1 & 1 \\
\hline Other & 5 & $\mathbf{1 0}$ \\
\hline Total & $\mathbf{6 5}$ & \\
\hline
\end{tabular}

Collectively, the interview participants did not favour having the HPE teacher who was without HE training to deliver HE as they perceived these teachers were lacking sociocultural understandings to explore the myriad of ways in which to think about health. They felt that these teachers were 'thrown in' to deliver HE at the deep end and they complained that these teachers avoided content, did very little planning, lacked passion, left things to the last minute and felt uncomfortable with the subject. One participant explained: "they see themselves as 'phys-edders' and not 'health-edders' and it is not their learning area as such." Whilst other participants complained about the impact of pre-service teachers without HE training on practicum in their schools, one participant stipulated that the choice of university in WA affected the delivery of HE in a pre-service teacher's classroom.

Nationally and internationally, a raft of critique explores teacher preparations in HPE, identifying teacher education institutions as the key site to unpack the bundles of knowledge that constitute contemporary HPE (Evans et al., 2004; Swabey et al., 2010; Tinning, 2000, 2004). Cliff (2007) explains that HE is grounded in a constructivist view of health, whilst PE in its entirety, does not reflect a social view of health. Cliff, along with researchers like Tinning (2014) implore universities to disrupt narrow understandings of HPE to allow more inclusive HPE teacher identities to emerge.

\section{Challenges and opportunities}

\section{University course design}

In 2016, the author of this paper received a grant from the university in which she is currently employed, to support the development of a new course for the university's pre-service secondary HPE teachers. This development aimed to align the proposed course with the preferred and holistic perspective of HPE articulated in the WA P-10 Syllabus for HPE and the endorsed AC: HPE (Australian Curriculum, 2015; School Curriculum and Standards Authority, 2015). This development includes the critical examination of the university's current course, along with the course structures and unit inclusions at other universities that prepare HPE preservice secondary teachers in WA and Australia.

In addition to the review, this development will explore the perspectives of curriculum leaders of HPE in WA schools through semi-structured interviews held with a sample of Heads of the HPE learning area (HOLAs). This development will gather contextual understandings of workplace 
needs and uncover some of the challenges and opportunities for graduate teachers in these schools. This development seeks to promote continuous open dialogue between schools and the university, with annual conversations to review progress and promote reflective practice.

Understandings from the review will be combined with the perspectives of the HOLAs to develop a contemporary and reflective course that prepares pre-service secondary HPE teachers to advance the effective delivery of the full scope of educational outcomes for HPE, whilst promoting skills that will help them navigate the variously positioned secondary schools across WA.

\section{Professional learning}

'Out-of-field' teaching is not exclusive to HE nor to WA and in regard to HE, it is no longer education's "dirty little secret" as claimed by Ingersol in 2003 (cited in McConney \& Price, 2009 , p. 88). In fact, it is prolific in the subject of HE in WA secondary schools and largely a consequence of contextual and administrative constraints and contingencies (Barwood, 2015a).

At the same time, specific professional learning that supports 'out-of-field' teachers to deliver $\mathrm{HE}$ effectively, which unpacks the theory and practice underpinning health curriculum, does not exist in WA. This is despite the incidence of 'out-of-field' teaching within the subject being greater than other subjects in secondary schools (du Plessis et al., 2014; Goos, 2013; McConney \& Price, 2009; Sharplin, 2014). Professional learning is available to these teachers but it primarily focuses on content knowledge rather than policy and curriculum understandings.

Accordingly, appropriate professional learning is critically needed to help 'out-of-field' teachers to unpack the curriculum, and to explore the tenets, philosophies, ideologies and pedagogies that are within. Professional learning is needed that dissects and disrupts individualism in health learning and promotes inclusive practice and embraces diversity. In brief, professional learning is needed to help 'out-of-field' teachers build the capacity to sympathetically intervene, facilitate and educate in a HE classroom. However, and aside from promoting meaningful and valuable spaces for health learning, professional learning is needed for these teachers to enhance teacher comfort, confidence and competence and importantly in Australia, so that they can achieve within the context of HE the Australian Professional Standards for Teachers (Australian Institute for Teaching and School Leadership, 2011a).

\section{Final words}

The author acknowledges that course review and redesign in teacher education institutions is by no means easy, nor is it a 'quick fix' but more so, it is a continual work in progress. She acknowledges that her efforts in this paper do not offer new direction or re-imagine HE delivery but that, they recognise the gaps in our understandings and shed some new light on opportunities for change. Like Leahy et al. (2016), the author agrees that "more research, conversations and sharing" (p. 145) is needed, but unlike Leahy et al (2016), she would like to firmly reposition the spotlight to clearly illuminate HE practice. In refocusing some of our research efforts toward generating more empirically-based understandings of our practice, then the relationship between policy, context and teacher preparedness to teach HE can be better understood. 


\section{References}

Australian Curriculum, Assessment and Reporting Authority. (2015). The Australian Curriculum: Health and Physical Education. Sydney, Australia: Author.

Australian Institute for Teaching and School Leadership. (2011a). Australian professional standards for teachers. Melbourne, Australia: Author Retrieved from http://www.aitsl.edu.au/ australian-professional-standards-for-teachers.

Australian Institute for Teaching and School Leadership. (2011b). National professional standards for teachers. Retrieved from http://www.aitsl.edu.au/verve/_resources/AITSL_National_Professional_ Standards_for_Teachers.pdf

Barwood, D. (2015a). What we know, what we do and what we could do: Creating an understanding of the delivery of health education in lower secondary government schools in Western Australia. (Unpublished doctoral thesis), Edith Cowan University, Perth, Western Australia.

Barwood, D. (2015b). What we know, what we do and what we should do with regard to the delivery of health education in lower secondary governement schools in Western Australia. Paper presented at the Values into action - A brighter future: Edited proceedings of the 29th ACHPER International Conference, Adelaide, Australia.

Barwood, D., Cunningham, C., \& Penney, D. (2017). What we know, what we do and what we could do: Creating an understanding of the delivery of health education in lower secondary government schools in Western Australia. Australian Journal of Teacher Education, 41(11), 15-30. doi:10.14221/ajte.2016v41n11.2

Begoray, D. L., Wharf-Higgins, J., \& MacDonald, M. (2009). High school health curriculum and health literacy: Canadian student voices. Global Health Promotion, 16(4), 35-42. doi:10.1177/1757975909348101

Burrows, L., \& Wright, J. (2004). The good life: New Zealand children's perspectives on health and self. Sport, Education and Society, 9(2), 193-205. doi:10.1080/1357332042000233930

Cliff, K. (2007). A sociocultural perspective as a curriculum change in health and physical education. (Unpublished doctoral thesis), University of Wollongong, New South Wales.

Daube, M. (2011, May 16). Alcohol education the key to a better lifestyle. The West Australian, p. 18.

Du Plessis, A. E., Gillies, R. M., \& Carroll, A. (2014). Out-of-field teaching and professional development: A transnational investigation across Australia and South Africa. International Journal of Educational Research, 66, 90-102. doi:10.1016/j.ijer.2014.03.002

Education Department of Western Australia. (1986). The unit curriculum: Introduction. Perth, Australia: Author.

Education Department of Western Australia. (1987a). The unit curriculum: Health education (Personal and Vocational education). Perth, Australia: Author.

Education Department of Western Australia. (1987b). The unit curriculum: Physical education. Perth, Australia: Author.

Evans, J., Davies, B., \& Wright, J. (2004). Body knowledge and control: Studies in the sociology of physical education and health (J. Evans, B. Davies, \& J. Wright Eds.). London, England: Routledge.

Fetherston, T. (2011). Artichoke (Software programme). Retrieved from http://artichokesoftware.com/

Fetro, J. V. (2010). Health-literate youth: Evolving challenges for health educators. American Journal of Health Education, 41(5), 258-264. doi:10.1080/19325037.2010.10599152 
Goos, M. (2013). How other learning areas managed implementation - the case of mathmatics. Paper presented at the HPE national curriculum implementation: Provocations, challenges and responses, Brisbane.

Harris, J., \& Leggett, G. (2013). Influences on the expression of health within phsycial education curricula in secondary school in England and Wales. Sport, Education and Society. doi:10.1080/1 3573322.2013.853659

Hattie, J. (2003). Teachers make a difference: What is the research evidence? Melbourne, Australia: Australian Council for Education Reseach.

Hattie, J. (2005). What is the nature of evidence that makes a difference? Using data to support learning. Paper presented at the The 10th National research conference of the Australian Council for Educational Research, Camberwell, Victoria.

Hattie, J. (2009). Visible learning: A synthesis of over 800 meta-anlyses relating to achievement. London, England: Routledge.

Kann, L., Brener, N. D., \& Allensworth, D. D. (2001). Health education: Results from the school health policies and programs study 2000. Journal of School Health, 71(7), 266-278. doi:10.1111/j.1746-1561.2001.tb03504.x

Leahy, D., Burrows, L., McCuaig, L., Wright, J., \& Penney, D. (2016). School health education in changing times: Curriculum, pedagogies and partnerships. Oxon, England: Routledge.

Lohrmann, D. K. (2011). Thinking of a change: Health education for the 2020 generation. The American Journal of Health Education, 42(5), 258-269. doi:10.1080/19325037.2011.10599196

Mayer, A. B., Smith, B. J., \& McDermott, R. J. (2011). Health education: Always approved but still not always on schools' radar. The American Journal of Health Education, 42(6), 349-359. doi:10.1080/ 19325037.2011.10599206

McBride, N., Midford, R., \& Cameron, I. (1999). An empirical model for school health promotion the Western Australian school health project model. The Health Promotion International, 14(1), 17-25. doi:10.1093/heapro/14.1.17

McConney, A., \& Price, A. (2009). Teaching out-of-field in Western Australia. Australian Journal of Teacher Education, 34(6), 86-100. doi:10.14221/ajte.2009v34n6.6

Ministerial Council for Education, Employment, Training and Youth Affairs. (2008). Melbourne declaration on educational goals for young Australians. Retrieved from http://www.mceecdya.edu.au/.

Paakkari, L., Tynjala, P., \& Kannas, L. (2010). Student teachers' ways of experiencing the teaching of health education. Studies in Higher Education, 35(8), 905-920. doi:10.1080/03075070903383229

School Curriculum and Standards Authority, Western Australia. (2015). WA P-10 Syllabus for Health and Physical Education. Perth, Australia: Author.

Sharplin, E. D. (2014). Reconceptualising out-of-field teaching: Experiences of rural teachers in Western Australia. Educational Research, 56(1), 97-110. doi:10.1080/00131881.2013.874160

Shilton, T., McBride, S., Cameron, I., \& Hall, M. (1995). Advocacy for school health: The power of data. Health Promotion Journal of Australia, 1(5), 24-29.

Sinkinson, M. (2011). Back to the future: Reoccurring issues and discourses in health education in New Zealand schools. Policy in Education, 9(3), 315-327.

Smith, W., \& Philpot, R. (2011). The Preparation of HPE teachers in New Zealand. Asia-Pacific Journal of Health, Sport and Physical Education, 2(3-4), 71-80. doi:10.1080/18377122.2011.9730360 
Swabey, K., Castleton, G., \& Penney, D. (2010). Meeting the standards? Exploring preparedness for teaching. Australian Journal of Teacher Education, 35(8), 29-46. doi:10.14221/ajte.2010v35n8.3

Tinning, R. (2000). Seeking a realistic contribution: Considering physical education within HPE in New Zealand and Australia. Journal of Physical Education New Zealand, 33(3), 8.

Tinning, R. (2004). Rethinking the preparation of HPE teachers: Ruminations on knowledge, identity, and ways of thinking. Asia-Pacific Journal of Teacher Education, 32(3), 241-253. doi:10.1080/1359866042000295406

Tinning, R. (2014). Getting which message across? The (H)PE teacher as health educator. In K. Fitzpatrick \& R. Tinning (Eds.), Health education: Critical perspectives. Oxon, England: Routledge.

Western Australia Curriculum Council. (1998). Curriculum framework for kindergarten to year 12 education in Western Australia. Osborne Park, Australia: The Council.

Western Australia Education and Health Standing Committee. (2011). Alcohol: Reducing the harm and curbing the culture of excess. Perth, Australia: Legislative Assembly, Parliament of Western Australia. 